\title{
A COMPUTER PROGRAM FOR THE
} REDUCTION OF DIFFUSE X-RAY DATA FROM SOLID SOLUTIONS

\author{
R. O. Williams
}

\section{MASTER}

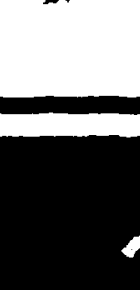




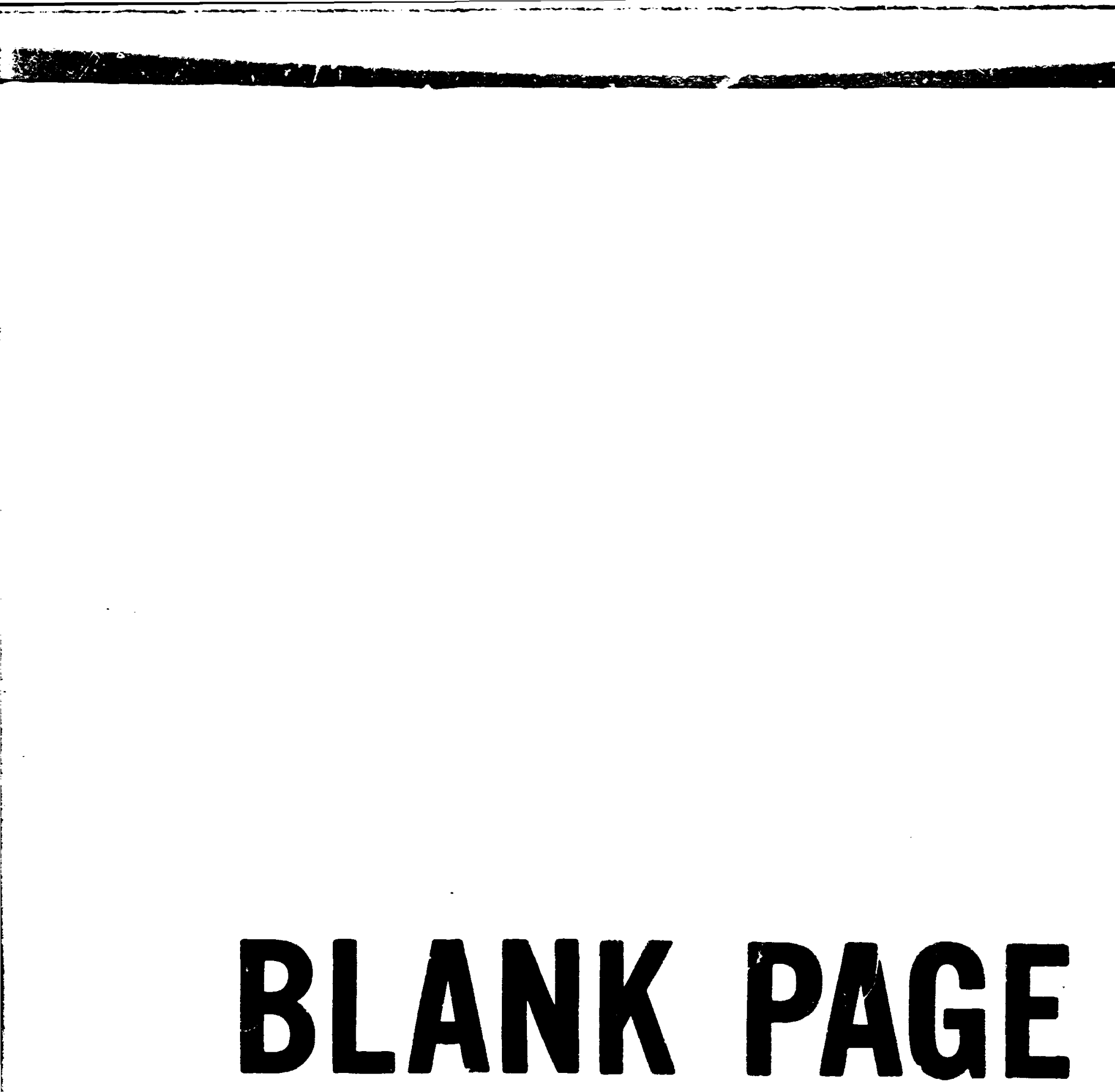


Pristed in tt a United States of America. Available from National Technical Information Service

US. Depertment of Commerce

5285 Port Royal Rosd, Springfield, Virginis 22151

Price: Printed Copy \$3.00; Microfictie \$0.95

This repon wos prepared es en account of work sponsored by the United Stutes Government. Neither the United Stetes nor the United States Atumic Energy Cornmission. nor any of their employees, nor any of their contractors, subcontractors, or their employees, makes any verranty, express or implied, of asumes eny legel liability or responsibility for the sccuracy, competeness or usefulness of any information, apparatus, protuct or prosess disslosed, or represents that its use would not infringe privately owned rights. 


\author{
ORM, $-4,28$ \\ UC-25 - Metais, Cc: anics, and Materials
}

Contract No. W-7405-eng-26

METALS AND CERAMICS DIVISION

A COAPUTER PROBRAY POR THE REDUCTION OF DIFFUSE X-RAY

DATA FROM SOLID SOLUTIONS

R. 0. Willians

OCTOBER 1972

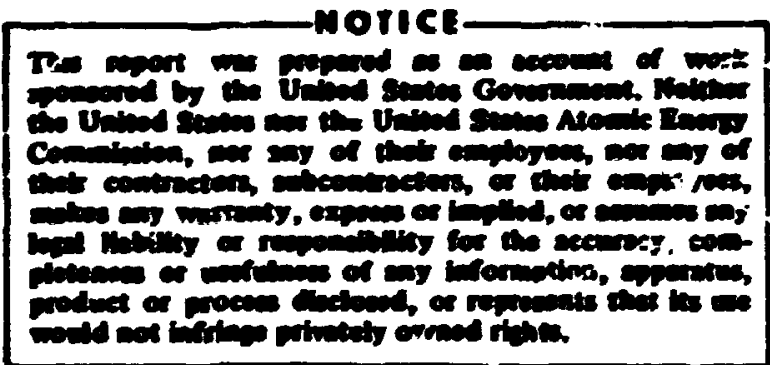

OAK RIDGE MATIONAL LABORATORY

Oak RIdge, Tennessee 37830

operated by

LAION CARBIDE CORPCAATION

for the

U.S. ATUMIC ENERGY COMJSSION 
coirtarirs

Page

Abstract ............................ 1

Introduction . . . . . . . . . . . . . . . . . . 1

X-Ray Theury . . . . . . . . . . . . . . . . . . . . 2

Solution of the Diffraction Equation . . . . . . . . . . . . 5

Statistics . . . . . . . . . . . . . . . . 10

Description of the Progran . . . . . . . . . . . . . 12

Changes in the Progran ..................... . 17

Testing. . . . . . . . . . . . . . . . . . . . . 19

Discussion . . . . . . . . . . . . . . . . . . 19

Acknowledgnent . . . . . . . . . . . . . . . . . . . 20

Appendix A . . . . . . . . . . . . . . . . . . . . . 21

Appendix B . . . . . . . . . . . . . . . . . . . . 29 


\section{A COMPUTER PROGRAY FOR THE REDUCTION OF DIFFUSE X-RAY} DATA FROM SOLID SOLUTIONS

R. 0. Williams

\section{ABSTRACT}

This report documents a computer program to reduce the diffuse $x$-ray scattering data from cubic alloys by a multiple regression analysis. The solution provides information on the short-range order and the atonic displacenents. The advantages of the present method are that it provides increased freedom in making observations, fewer approximations are required, and a complete error analysis is obtained.

\section{INTRODUCTION}

Over the past 25 years it has been realized that metallic siild solutions are rather complex in that the atoms need not be randomly distributed nor sit precisely on the lattice sites. These irregularities produce diffuse diffraction of $x$-rays, which is quite distinct from the sharp Bragg diffraction. A number of experimental methods are capable of studying such effects, but the most extensive and unabiguous information comes from this diffuse scattering. Although only a ew systems have been extensively studied, the results are very interesting in the considerable variety of observed effects. Ultimately such studies should be very important in developing theories of solutions concerning, for example, the heat of mixing, size effects, flow strength, anelasilic properties, ordering, and precipitation.

The total coherent diffuse scattering is the sum of three contributions: short-range orter, first-order displacenents, and second-order displacements (which include thermal diffuse scattering, TDS). The observations are to be restricted such that higher terms can be ignored. Borie and Sparks ${ }^{2}$ showed that as a result of the differint symetries of

\footnotetext{
'B. S. Borie and C. J. Sparks, Jr., Actx Cryst. A27: 198-201 (1971).
} 
these contributions the total intensity can be separated into components that depend only on a single effect such that the desired parameters car be obtained from a Fourier analysis. This treatment is a recent development, and only a few systems heve bean fully analyzed. ${ }^{2-5}$

The intensity is a linear function of parameters that ifscribe each contribution. is follows, therefore, that a solution can also be obtained by a standard multiple regression analysis (also known as least-squares fitting). This report documents the program for carrying out this analysis. A principle advantage of this method over the separation technique ${ }^{l}$ is that one ottains estinates of the parameter errors and their correlation.

The metinod has been applied to a reanalysis of the data on Cu-16 at. I A by Borie and Sparks, ${ }^{6}$ and the results ar: to be covered elsewhere.?

\section{X-RAY THEORY}

The intersity, in electron vnits, of $x$ rays scattered from any material is give: by

$$
I=\sum_{u} \sum_{v} f_{u} f_{v} e^{i \underline{k} \cdot\left(\underline{R}_{u}-\underline{\mathbf{R}}_{v}\right)},
$$

where the atoiss at sites $u$ and $v$ have atomic scattering factors of $f_{u}$ and $f_{\eta}$, and a relative position of $\mathrm{R}_{u}-\mathbb{R}_{v}$, and $\mathrm{k}$ is defined below. For a cul ic lattice we may define a position $\mathbf{i n}$ reciprocal space by the vector $\underset{\sim}{\mathbf{h}}$ as

$$
\underline{h}=\underline{h}_{1}+\underline{h}_{2}+\underline{h}_{3} \text {, }
$$

${ }^{2}$ W. Lin, J. E. Spruiell, and R. 0. Wiillams, J. Appl. Cm!st. 3: 297-305 (1970).

${ }^{3}$ W. Lin and J. E. Spruie11, Acta Met. 19: 451-61 (1971)

4J. E. Gragg, Jr., and J. B. Cohen, Acta Met. 19: 507-19 (1971).

${ }^{5}$ T. Ericsson and 1. B. Cohen, ficta Cryst. A27: 97 (197i).

${ }^{6}$ B. Borie and C. J. Sparks, Jr., Acta Cryst. 17: 827-35 (1964).

7R. O. Williams, "Short-Range Structure in a Copper 16 Awific Percent Aluminum," to be submitted for publication. 
where the components are in the directions of the cube edges. This vector is given by

$$
\underline{\underline{h}}_{1}+\underline{\underline{h}}_{2}+\underline{\underline{h}}_{3}=\left(\underline{S}-\underline{S}_{0}\right) a_{0} / 2 \lambda,
$$

where $\underline{S}_{0}$ and $\underline{S}$ are the unit vectors defining the incident and diffracted bean of wave length $\lambda$ and $a_{0}$ is tine lattice parameter. Since

$$
\underline{\mathbf{k}}=2 \pi\left(\underline{\underline{S}}-\underline{\mathbf{S}}_{0}\right) / \lambda \text {, }
$$

it follows that

$$
\underline{\mathbf{k}}=4 \pi\left(\underline{\underline{h}}_{1}+\underline{\underline{h}}_{2}+\underline{\underline{h}}_{3}\right) / a_{0} .
$$

The relative location of a pair of atoms in an fcc or bce lattice can be expressed as

$$
\underset{\sim}{\mathrm{R}_{u}}-{\underset{\sim}{\mathrm{R}}}_{v}=\frac{1}{2}\left[\left(2+\delta_{\eta}\right) \mathrm{a}_{1}+\left(m+\delta_{m}\right) \mathrm{a}_{2}+\left(n+\delta_{n}\right) \mathrm{a}_{3}\right],
$$

where $Z, m$, and $n$ are integers corresponding to the average lattice, the $a^{\prime} s$ arc the cube edges, and the $\delta$ 's are the components of the deviation from the average lattice vector.

Since we obtain an overall average from dffiraction experiments, the double sum in Eq. (1) may be replaced by a single sum over $N$ average sites. We may further expand the exponential tere through the quadratic term in $\delta$, the imaginary parts being zero because of symetry. For a binary alloy we have

$$
\begin{aligned}
\frac{I}{\nabla f_{A}^{2}}= & \sum_{i}^{\infty}\left[\left(A+B f_{B} / f_{A}\right)^{2}+\alpha A B\left(1-f_{B} / f_{A}\right)^{2}\right] \sum \cos 2 \pi\left(h_{1} z+h_{2} m+h_{3} n\right) \\
& +2 \pi A B\left(f_{B} / f_{A}-1\right) \sum_{i=1}^{\infty} \gamma \sum h_{j} \sin 2 \pi\left(h_{1} z+h_{2} m+h_{3} n\right) \\
& -2 \pi^{2} A B \sum_{i}^{\infty} \varepsilon \sum h_{j}^{2} \cos 2 \pi\left(h_{1} z+h_{2} m+h_{3} n\right) \\
& -4 \pi^{2} A B \sum_{i}^{\infty} \rho\left[h_{j} h_{k} \cos 2 \pi\left(h_{1} z+h_{2} m+h_{3} n\right),\right.
\end{aligned}
$$


where $A$ and $B$ are the atumic fractions and $\alpha$ is the Warren-Cowley order parameter defined as

$$
\alpha_{i}=1-P_{i} / B
$$

where $P_{i}$ is the probability of finding a $B$ atom in a particular site in the $i$ th shell around an $A$ atom. Necessarily $\alpha_{0}=1$, and for a random alloy all the $\alpha^{\prime}$ s for $i \neq 0$ are zero. The outer sums are over successive stells $(i)$, while the inner sums are over the cosine or sine terms corresponding to the permutations and combinatious of $l, m$, and $n$ that describe the positions of all the sites in the particular shell. Also

$$
\gamma_{j}=\left(\frac{A}{B}+\alpha_{i}\right) \delta_{\mathrm{AA}}^{j}-\left(\frac{B}{A}+\alpha_{i}\right) \frac{f_{\mathrm{B}}}{f_{\mathrm{A}}} \delta_{\mathrm{BB}}^{j},
$$

where the $\delta_{\mathrm{AA}}^{j}$ is now the average of one of the three $\delta^{\prime}$ 's defined in Eq. (6) for A-A pairs in the $i$ th shell; similarly for $\delta_{\mathrm{BB}}^{j}$. For cach kind of pair there will be three $\delta^{\prime}$ 's for each shell, but symmetry requires that $\delta_{Z}=0$ if $l=0$ and $\delta_{l}=\delta_{m}$ if $l=m$. The displacement between unlike pairs $\therefore . s$ eliminated by the requirement of volume conservation. The particular $h_{j}$ in the sum is that $h$ in the sine term multiplied by the index $2, m$, or $n$ that corresponds to the particular $\delta$.

- The quadratic term is given as

$$
\varepsilon=\left(\frac{A}{B}+\alpha\right) \delta_{\mathrm{AA}}^{2}+2(1-\alpha) \frac{f_{\mathrm{B}}}{f_{\mathrm{A}}} \delta_{\mathrm{AB}}^{2}+\left(\frac{B}{A}+\alpha\right) \frac{f_{\mathrm{B}}^{2}}{f_{\mathrm{A}}^{2}} \delta_{\mathrm{BB}}^{2},
$$

where there will in general be a different $\varepsilon$ for each component of a shell and $\varepsilon_{\tau}=\varepsilon_{m}$ only if $\tau=m$. Note that $\delta^{2}$ is in reality $\left\langle\delta^{2}\right\rangle$ such that $\varepsilon_{l} \neq 0$ even when $l=0$. The $\varepsilon^{\prime} s$ cannot be negative since none of the terms on the right side of Eq. (9) can be negative. The $h_{j}$ in the second sum. Is identified as in the previous term. One sees that the displacement between unlike pairs must be retained in this expression.

The cross term is given as

$$
\rho_{l m}=\left(\frac{A}{B}+\alpha\right) \delta_{\mathrm{AA}}^{2} \delta_{\mathrm{AA}}^{m}+2(1-\alpha) \frac{f_{\mathrm{B}}}{f_{\mathrm{A}}} \delta_{\mathrm{AB}}^{2} \delta_{\mathrm{AB}}^{m}+\left(\frac{B}{A}+\alpha\right) \frac{f_{\mathrm{B}}^{2}}{f_{\mathrm{A}}^{2}} \delta_{\mathrm{BB}}^{2} \delta_{\mathrm{BB}}^{m}
$$


There will in general be three such terws for each sheil, but $\rho_{2 m}=0$ if $l$ or $m=0$. The $h_{j}$ and $h_{k}$ in the second su are identified as those multiplying the index $l$ and $m$ as for the previous terms.

It is of interest to physically identify the toras in Eq. (7). The first term is the relatively unifor Bragg intensity, which is collected by the cosine sum into the sharp peaks. The first member of the alpha series is the monotonic Laue intensity, which is redistrihuted by the cosine series. Normally the alpha series converges such that this intensity is not sharp. However, for perfect long-range order this intensity is collected into sharp superlattice peaks. The gama terms are called the first-order size effect. Since thermal motion has a zero time-average displacenent, it cannot contribute to these teras. One expects that these linear terns will converge because this is a necessary condition for the existence of an average lattice that gives sharp Bragg peaks.

Both static and dynamic (thermal) displacements contribute to quadratic terms, and these terms becone greater with larger shells. Since these terms do not converge, they correspond to a negative delta function at the Bragg peaks and in effect take some of the Bragg inteisity ar.1 redistribute it in reciprocal space. If the displacenents we:e all independent then all the $\varepsilon^{\prime} s$ would have the same value, so the quadratic diffuse intensity would be uniform except for the delta function.

\section{SOLUTION OF THE DIFFRACTION EQUATION}

Borie and Sparks $^{8}$ showed that the observations can be decomposed Into separate functions that depend only on $\alpha, \gamma, \varepsilon$, and $\rho$ as a result of the particular $h$ dependence of $\mathrm{Eq}$. (7). These parameters are then obtained by a Fourier transform. This method has been used by several investigators ${ }^{2-5}$ and represents the most detailed analysis of diffuse scattering that has been made. Alternately, since the intensity Is a linear combination of $\alpha, \gamma, \varepsilon$, and $\rho$ as shown in Eq. (7), then in theory we can apply a multiple regression analysis to fit the observations in terms of these series. The $\alpha$ and $\gamma$ series are well behaved

\footnotetext{
${ }^{8}$ B. S. Borle and C. J. Sparks, Jr., Acta Cryst. A27: 198-201 (1971).
} 
for short-range order, but unfortunately the $\varepsilon$ and $\bar{\rho}$ series do not converge; hence this method is not strictly applicable. Before a ufficient number of $\varepsilon$ and $\rho$ terms can be evaluated to properly represent .his component of Intensity the solution becomes so 111 conditioned that useful values are not obtained. The long-wavelength TDS, which has maxima at the Bragg peaks, is the primary cause of this difficulty. This intensity can be represented as follows.

Long-wavelength TDS is properly treated in terms of an elastic continiuen and is defined by only three eiastic constants for cubje matericls. A discrete lattice gives rise to dispersion such that the diffuse intensity decreases less rapidly with decreasing wavelength than predicted by the continium treatment. It also shows the symetry dictated by the lattice. The entire diffraction problem can be treated in terms of tine Born-von Rarman model in which the lattice dynamics are derived in terms of near neighbor interactions. 9 ,io We want our expression to approach the long-wavelangth limit, so we can use only three independent interaction constants. For the fcc lattice we may use the three parameters for the first neighbor. A rigorous application requires the solution of the secular equations for esch position in reciprccal space, but, following Houston, ${ }^{11}$ we are able to adequately represent the angular dependence by simple geometric expressions.

The relation between the three first neighbor isteraction parameters and the elastic constants are given as

$$
\alpha_{1}=a C_{11} / 4, \quad B_{1}=a C_{44} / 2-a C_{11 / 4}, \quad \gamma_{1}=a C_{12} / 4+a C_{44} / 4 .
$$

These may be uired in Eqs. 11.65-.67 in. Warren ${ }^{9}$ to describe the three elastic waves in each of the three symmetry directions. The more general

\footnotetext{
${ }^{9}$ B. E. Warren, X-ray Diffraction, Addison-Wesley, Reading, Massachusetts, 1969.

${ }^{10} \mathrm{C}$. B. Walker, Phys. Rev. 103: 547 (1956).

${ }^{1}$ W. V. Houston, Rev. Mod. Phys. 20: 161 (1948).
} 
expresat: : $:$ now approximated as

$$
\begin{gathered}
I_{11}=\frac{\omega_{l}^{2} m}{a C_{11}}=\left[1+(Y-1) r_{L}-P_{123}\right] S 1+\left[(1+X+Y) P_{L}+(1+2 X+4 Y) F_{123}\right] S 2,(12 \mathrm{a}) \\
D_{2}=\frac{\omega_{t 1}^{2} m}{a C_{11}}=Y\left(1-P_{123}\right) S 1+\left[(1-X-Y) P_{t 1}+(1-X+Y) P_{123}\right] S 2,(12 \mathrm{~b}) \\
D_{3}=\frac{\omega_{t 2}^{2} m}{a C_{11}}=\left[(1-Y) P_{t 2}+\left(1-P_{123}\right) Y\right] S 1 \\
+\left[(2 Y-1) P_{t 2}+(1-X+Y) P_{123}\right] S 2,
\end{gathered}
$$

where

$$
\begin{gathered}
X=C_{12} / C_{11}, Y=C_{44} / C_{11} ; \\
P_{t_{1}}=4 \cos ^{2} \phi_{1} \cos ^{2} \phi_{2}\left(1-3 \cos ^{2} \phi_{3}\right) \\
P_{t 2}=4 \cos ^{2} \phi_{3}\left(\cos ^{2} \phi_{1}+\cos ^{2} \phi_{2}-6 \cos ^{2} \phi_{1} \cos ^{2} \phi_{2}\right) \\
P_{L}=P_{t 1}+P_{t 2}, \text { and } \\
P_{123}=27 \cos ^{2} \phi_{1} \cos ^{2} \phi_{2} \cos ^{2} \phi_{3} ;
\end{gathered}
$$

with angles defined in Fig. 1 , and

$$
S 1=4 \sin ^{2} \pi g_{x}, S 2=\sin ^{2} 2 \pi g_{x}
$$

Our $\underset{g}{g}$ vector is in the same units as our $\underset{\sim}{h}$ vector, Eq. (3), $g_{x}$ being the largest component.

The thermal diffuse intensity is now given by Eq. (11.35) in Warren $^{9}$ as

$$
\frac{I}{N f_{\mathrm{A}}^{2}}=\left(\frac{A f_{\mathrm{A}}+B f_{\mathrm{B}}}{f_{\mathrm{A}}}\right)^{2} c|\underset{\sim}{\mathrm{h}}|^{2} \sum_{j=1,3} \frac{\cos ^{2}\left(\underset{\left.\mathrm{h}, \mathrm{e}_{j}\right)}{D_{j}}\right.}{D_{j}},
$$




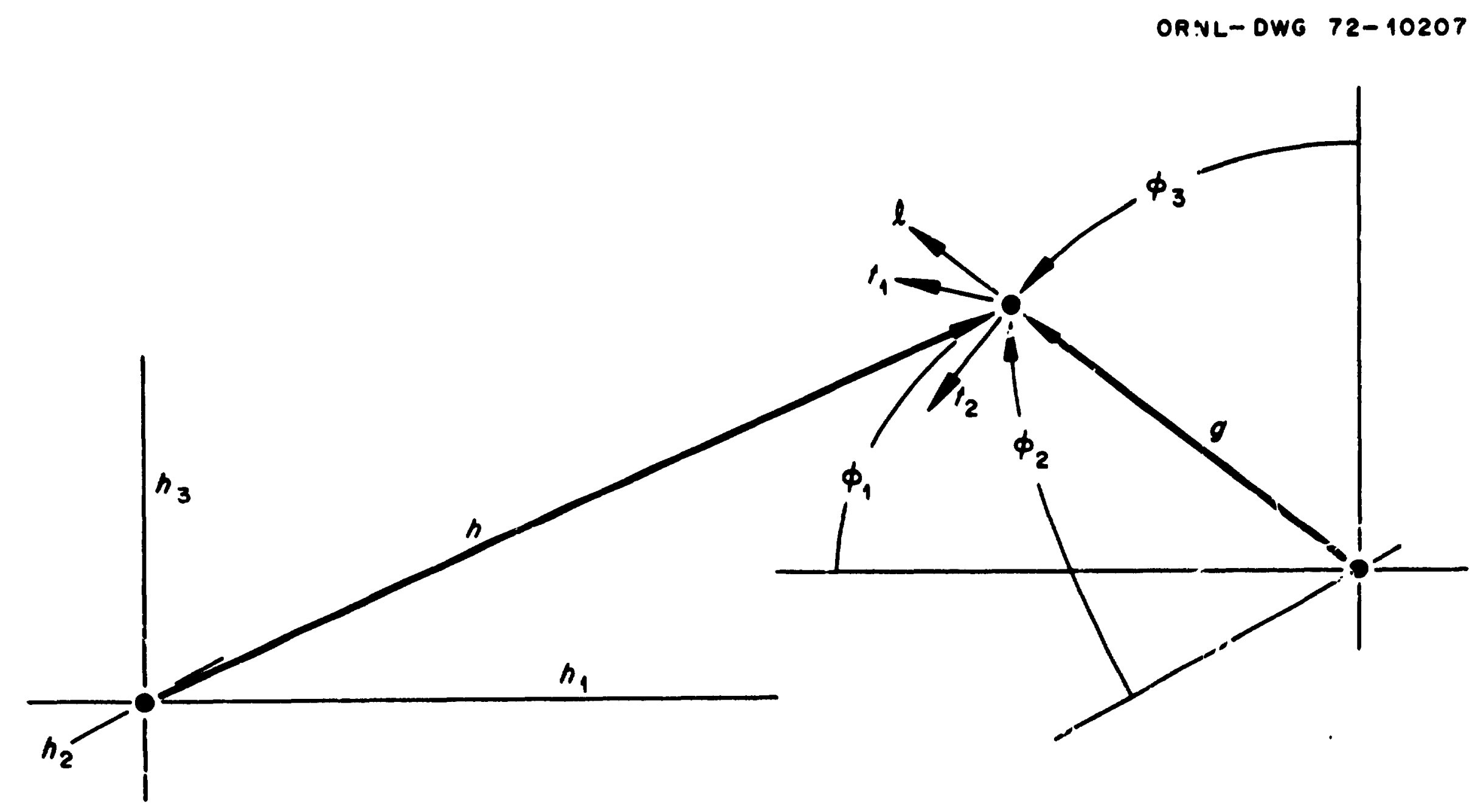

Fig. 1. The Relation Between an viservation at Reclprocal Lattice Puint $h$, Which is In a Brillouin Zone Centered at $g=0$. The longitudinal wave is taken to be parallel to $g$. For the two traneverse waves $t_{1}$ has zero $h_{3}$ displacement and $t_{2}$ ls tangent to arc $\phi_{3}$ at 8 . 
where $\left(\underline{h}, e_{j}\right)$ is the angle between $\underline{\sim}$ and the displacement of the $j$ th wave, which is defined in $\mathrm{Ifg}$. 1. The value of $C$ is to be obtained by the regression analysis; from this result,

$$
C_{11}=16 \pi^{2} K \cdot T / a_{C}^{3} C
$$

where $K$ is the Boltzmann constant and $T$ the temperature.

Methods for solving for nonlinear terms such as $X$ and $Y$ are known but are relatively more involved than evaluating linear coefficients. The included program uses the simpler approach of providing solutions for various combinations of $X$ and $Y$ based upon initial estimates. Since one must in general lesort to several solutions to obtain a wore or less optfaum combination of terms, there should be ample opportunity te establish satisfactory choices for $X$ and $Y$.

If this were a complete treatment, Bq. (16) would replace the $\varepsilon$ and the $\rho$ series in Eq. (7). Since it is not, one can still include low-order terms of these two series to ioprove the fit where the terms are now understood to represent that quadratic intensity not represented in our IDS expression. We would also include a term

$$
2 \pi\left(A+B f_{B} / f_{A}\right)^{2}|\underline{h}|^{2} \varepsilon_{0},
$$

where $\varepsilon_{0}$ is to be evaluated in the solution. The rationale for this tem is that if, for example, all the displacements were random, then we would only have a single term, which increased simply as $|\underline{h}|^{2}$. There would still be a negative delta function at the Bragg peaks, but this region is excluded from our observations.

We would hope that the $10 \%$-order terms of $\varepsilon$ and $\rho$ would compensate for the contribution by the static displacements, for the fact that we used only first neighbor interactions, and possibly in par. for the way we approximated the TDS.

We have intentionally left the $e^{-2 m}$ term out of Eq. $(16$, . Presumably one restricts the observations such that higher order TDS, which is not inciuded in Eq. (16), is unimportant, in which case $e^{-2 m}$ possibly may also be neglected. It should be included if it gives a siguificantly better 
fit and should also be included in the $\varepsilon_{0}$ term. Note that the value of $m$ is not independently adjustable since it wust have a value such that the intensity lost fion the Brags peaks is just that intensity in the TDS and $\varepsilon_{0}$ term. We would not require an $e^{-2 m}$ tern in the $\alpha$ series in Eq. (7), in contrast to the excression by Walker and Kesting, ${ }^{12}$ since the $\varepsilon$ and the $p$ terms now represent this effect. However, when we replace the $\varepsilon$ and $p$ serika by the IIs expression, such a term right now be in order; again an ilproved fit being sufficient justificatios.

\section{STATISTICS}

The present solution gives the values of the parameters, an estinate of their errors, and the correlation between the errors. Also a necessary part of the computations 18 the calculated intensity and the residuals, the differences between the observed intensity and the calculated intensity. Alhough it is not included in the present program, one can readily calculate the error in the observed intensity, or in any of its comonents. This Information helps to indicate where the observations are in greater error, but the residuals also give essentially the same information and also indicate the probable $81 \mathrm{gn}$ of the errors. The statistics that are user! are generally known and may be found in Hanilton, ${ }^{13}$ for example. Cerizin statistical aspects of the prisent problen require specisl considerstion.

The magnitudes of the paraweter errors are proportional to the residuals, but further, the present calculation is based upon the assumption that these residuals are random. Formally, there is no problem if this is not so since then one needs only to ir:lude in the weighting atrix the offdiagonal terms that result from the correlation between the ercors in the data. For the present problen this is of no help since in the first place very little is known about the correlations, and in the second place a full weighting matrix makes the st.ze of the problem prohibitive. One could undoubted ly reformulate the progran to accomodate correlations between

${ }^{12}$ C. B. Walker and D. T. Reating, J. Appl. Phys. 34: 2309 (1963). 1964.

$1{ }^{3}$ w.C.C. Hamilton, Statistics in Dhysical Science, Ronald, New York, 
Intessity that are close in reciprocal space, but this does not solve the first problem. A desirable solution would be the identification and reduction of such norrandon error3. Dropping the velghting factor entirely would not serfously degrad a the solution, but its inclusion does pernit certain conveniences.

The reader should realize that the paraneter errors are to be taken as random, and should the oisservations be blased, because of inproper bean standardizstion for exapie, then thw paraneters will also contain oid:tional biased errors. Grags et al. ${ }^{14}$ have recently consider id the orerall problew or eizors in such measurements.

It is important to realize that there is a basic difference between using a regression analysis and a Pourler anjlysts on the separated functions. For a given nuber of terms the regression analysis will give a superior fit, but as the nuber of terws increases at sone place the solvtion becomes 111 conditioned such that the terms in the solution will take on large, unreal magnitudes. This weans thot the solution is developing considerable sall-scale structure to better fit the obcervations. Thus ultimately the solution must becone unsatisfactory. We have shown elsewhere $^{15}$ how to Include very powerful supplementary conditions that restrfct such behavior and pernit the solution to be carried to alnost any length. A solution using a Fourier analysis cannot exhibit such improper behavior and in that sense 18 superior. In a very real sense the use of supplementary conditions accomplishes the same things that one may do in a Pourfer analysj.s, such as smoothing and filling in data at the Brags peaks. Such supplementary conditions degrade the degree of fit only very little and hence do not introduce any particular uncertainty in the estination of the errors. They do, however, greatiy reduce the magnitude of the error correlation, and thus constitute a very useful device. As a general rule one would Include sufficient terms in each series until the coefficients have magnitudes sinilar to their errors.

14J. B. Grags, Jr., M. Hayakawa, and J. B. Cohen, ACA Winter Heeting, Albuquerque, N.M., February 1972.

15R. 0. W1111ans, "Short-Range Structure in a Copper 16 Atontc Percent Aluninum," to be submitted for publication. 
A detalled exanution of the residuals can prove to be of considereble value. Ang gyotentic deviation between the observed and calculated Intenaities orer the field of masurement cust be due to linitations in the dats, In the expression belng fit to the date, or botb. Obviousiy the elinination of such problems can aterially ipprove the final results. Further, the residinals should show no significant correletion with any variable; such correlations provide a clue as to the natire of the difficulty. The documented progran provides information about the behavior of the restunals as fuctions of 20 .

\section{DEscription or TAR Prograx}

Because of the difficulties imvolved no attest has been made tu write a general progran that would accept data is any format. Rather, the Ifited progran was oritten to handle a specific set of observations, and this section provides the docunertation such that the user can make such changes as required. For problem of this conplexdty it is inportant that the user have a reasonable understanding of the program; else the chances of zajor errors are great. Having gained this understanding one can readily me the required nodifications.

The listed progran, Given in Appendix A, was designed zo evaluate the observations ${ }^{16}$ on a Cur-16 et. $\mathrm{Z} \mathrm{Al}$ crystal at $77^{\circ} \mathrm{K}$ usiag wonochromatic copper rediation. It accepts 4032 observationi and conputes 23 values of $\alpha, 17$ values of $r, 2$ values of $\varepsilon$, and one each of $\rho, \varepsilon_{0}$, and $\tau$, as defined by Bqs. (7) and (16). Ereh solution is repeated nine times, using the combinations of three dffferent values of $X$ and $\dot{Y}$. Tize observations conslated of the following sets:

Date Set

A
B
D

\begin{tabular}{|c|c|c|}
\hline \multirow[t]{2}{*}{ Rerion } & \multicolumn{2}{|c|}{ Range, deg.* } \\
\hline & $2 \theta$ & $\phi$ \\
\hline $\mathbf{B}_{1}-\mathbf{H}_{2}-\mathbf{H}_{3}=0,0=0$ at $[2 \overline{\mathbf{I I}}]$ & $20-136$ & $0-30$ \\
\hline $\mathrm{H}_{1}-\mathrm{H}_{2}-\mathrm{H}_{3}=0, \phi=0$ at $[2 \overline{11}]$ & $50-136$ & $1-31$ \\
\hline $\mathbf{H}_{3}=0, \phi=0$ at $[100]$ & $20-136$ & $0-44$ \\
\hline $\mathrm{H}_{3}=0, \phi=0$ at $[100]$ & $50-136$ & $1-43$ \\
\hline
\end{tabular}

*Incremants of $2 \theta$ and $\phi$ are $2^{\circ}$. thast trace at $45^{\circ}$.

I6. Borle and C. J. 3parks, Jr., Acta Cryst. 17: 827-35 (1964). 
We speak of the values of $\alpha, \gamma$, etc. collectively as the solution and the teras that rhey multiply in Bqs. (7) and (16) as the coefficients, which consist of two parts, the presu part and the geometric part.

The progran consists of :hree ain parts: DIFTUSE, which handles all the input and part of the output and which calls the subroutines; SERIES, which calculates the coefficients; and STAT, which carries out the regression analysis. STAT uses a subroutine MTQ for a eatrix inversion, whish is not included since the user can supply an equivalent subroutine. Progreming 18 considerably simplified by the use of six function-type subprograns that calculate the sines and cosines as required in the geonetric coefficients. A final function IRID(X) rounds $X$ to the closest integer. In this section FORThif stetements, varlables, and prograns are capitalized.

Table 1 identifies tise presum parts of the coefficients and gives the variable names used in the progran. To names ay be used in DIFTUSE; the dimensioned variable contajns ail required values, which are calculated in loop 6. The second nase 18 one that occurs in $\mathrm{Cow} / \mathrm{N} / \mathrm{C} /$, which provides access by SERIES. The final three variables locate the position of the observation.

Table 1. Variables Transferred Between Programs by corrom/ci

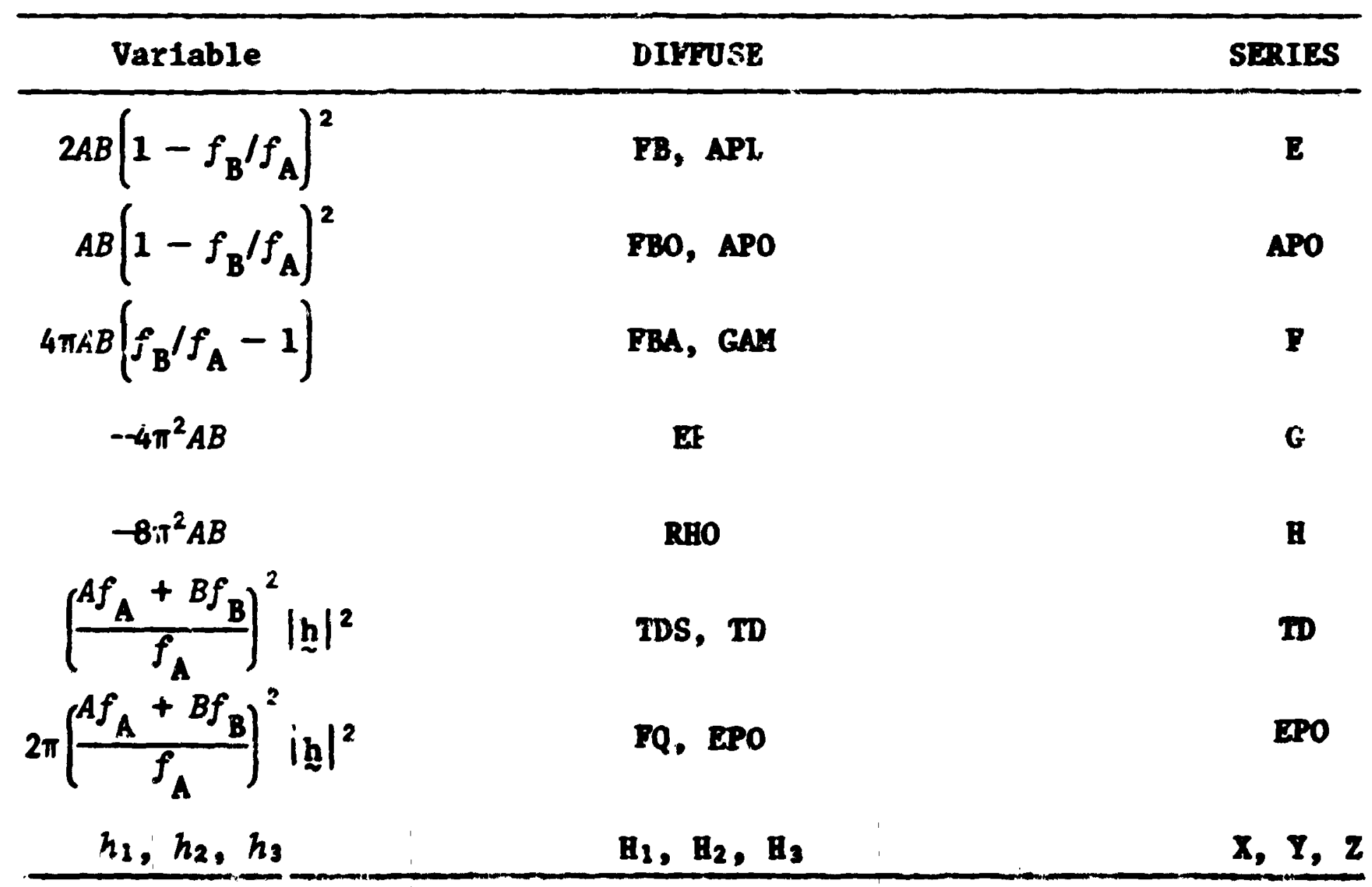


Labeled camon blocks are used to provide aciess to the different variables in the different parts of the progran. Extensive us: is made of the facility for breaking up a comon block differently in the different parts of the progran. This simplifies the progran, but the user mist understand how this works when aking changes and nay require professional help. The comon blocks are listed in Table 2 along with che nanes of the variables they contuin $i=$ different parts of the progran. As a opecific exaple canox/A/ confains the observed intensity as the four data sets listed in DIFFUSE, while in STAT these values are treated as a singls dimensioned variabile $A$.

We now prazeed through the progran, indicating what is being done and identifging the variables.

FAL and FCU are the atomic scattering factors of aluninum and copper in Increwents of $0.05 \mathrm{sin} \theta / \lambda$ starting with zero and are provided by the DATA statements. AIAM is the wavelength of the radiation; $A 0$ is the lattice parameter. The three values of $X$, Eq. (12) that are used are X12, X12+DX12, and XI2+20X12; sinilar11y for $Y, Y 44$ and DY44. XAE is the product of the compositions, and $B G$ will be used in the weighting function. Variables LL, MA, and NN are the integers that locate the atoms in the shells. They are of the form $200,220,227,2 \mathrm{mo}, 2 \mathrm{~mm}$, and $2 \mathrm{~mm}$ and are indicated by values of 1 through 6, respectively, in INDEX. Theze values are multiplied by $2 \pi$ in loop 39.

The next four loops read in the data. In loop 6 vie calculate those pa:ts of the coefficients that are a function of $2 \theta$ and $\phi$. WR is proportional to the area associated with each observation and will hecome part of the weighting functiou. The factor 0.002 simply controls the size of the numbers generated during the macrix inversion, thus reducing the possibility of overflows, but otherwise does not affect the solution. The term $59 /(I+43)$ drops from 1 to 0 wher I exceeds 16 to compensate for the way in which the observations interlace. Loop 20 sets WA, WB, WC, and UD to zero.

The next four loops proceed to calculate the reciprocal lattice coordinates for each observation, H1, H2, and H3, assigp the proper values to the verlables in COMYON/C/, and then call SERIES. These loops are 
Table 2. Contents of Labeled Common Blocks

\begin{tabular}{|c|c|c|c|c|}
\hline \multirow{2}{*}{ Block } & \multirow{2}{*}{ Variable } & \multicolumn{3}{|c|}{ Name of Variable in } \\
\hline & & DIFFUSE & SERIES & STAT \\
\hline $\mathbf{A}$ & $I / R f_{A}^{2}$ observed & $A, B, C, D$ & & $\mathbf{A}$ \\
\hline B & $I / R f_{A}^{2}$ calculated & $\mathbf{A I}, \mathbf{B I}, \mathbf{C I}, \mathrm{DI}$ & & B \\
\hline $\mathbf{F}$ & Weighting factor & MA, WB, WC, WD & & $\boldsymbol{v}$ \\
\hline D & Coefficients for & & & \\
\hline & $\alpha_{0}, a$ & & $A D, D$ & \\
\hline & $r$ & & B & D \\
\hline & $\varepsilon_{0}, \varepsilon, \rho$ & & c & \\
\hline & TDS & & $\mathbf{A}$ & \\
\hline G & $\alpha, \gamma, \varepsilon, \rho, c$ & $A \mathbf{x}$ & & $\Delta x$ \\
\hline
\end{tabular}

so arranged that the observations are considered sequencially as stored in coswoN/A/. The weighting function WA etc. Is taken to be proportional to WR and inversely proportioral to the observed intensity plus PG.

Certain observations will be missing, in particular those too close to the Bragg peaks, and such wissing values are excluded from the analysis by the simple expediency of setting the weighting factor to zero. . However, values for the calculated intensity will be obtained for all points.

Before considering in detall how the coefficlents are calculated in SERIES, we need to consider how many terms of each kind are required for each shell. Obviously only o.:e $\alpha$ applles, but for the other vartables there may be wore than one, as shown in the following:

\begin{tabular}{|c|c|c|c|}
\hline Type of Shell & $\gamma$ & $\varepsilon$ & $\rho$ \\
\hline 200 & 2 & $\tau, 0$ & \\
\hline 220 & 2 & $\tau, 0$ & 22 \\
\hline 222 & 2 & 2 & 22 \\
\hline $2 m 0$ & $i, m$ & $\tau, m, 0$ & im \\
\hline $2 \ln n$ & $z, m$ & $\tau, m$ & $2 m, n n$ \\
\hline $2 m n$ & $l, m, n$ & $l_{,} m, n$ & $2 m, 2 n, m n$ \\
\hline
\end{tabular}


Thus there is one linear term for each different nonzero component of the she11, a quadratic term for each different component, and a cross term for each distinct pair having nonzero components. Muitiple terms for a specific shell ar? calculated in the order given in the table. The nanes of the variabliss that will contain the coefficients are listed in Table 2. Loop 7 calctilates the complete set of coefficients for the first 11 shells. The quadratic and cross terms are temporarily stored as variable $C$ because wore are evaluated than will be used. Loop 42 transfers the required ones into CD. Loop 27 calculates the coefficients for the $\alpha$ terns for shells 12 through 22. Variables $D, B$, and CD mist be properly dimensioned such that each position is filled with a proper coefficient. It is permissible $\tau$ calculate more linear terms in loop 7 than required to fill B since the extra ones, which overflow into $C D$, are subsequently witten over with the correct coefficient. The functions SL, SLM, and SLN calculate a sine and cosine tern as required in the inner sums, the sire corresponding to $\mathrm{Sl}$, the cosine as $\mathrm{Cl}$, for example. We make no distinction between the $\varepsilon$ and $\rho$ terms apart from position, but the $\rho$ terus may be identified as having factors $H$ and two reciprocal lattice components. For loop 27 we only require the cosine terms which are calculated by functions $R, S$, or $T$. Before any of these six functions are called the components of the shell (times $2 \pi$ ) are loaded into unlabeled coiron, which is then accessed in calculating the sines and cosines.

Immediately following statement $27, \mathrm{XX}, \mathrm{YY}$, and $\mathrm{ZZ}$ are the components for the closest Brillouin zone havi 7 even Indices; X2, Y2, and 22 , the closest one with odd indices. The observation belongs to that zone having the smallest $g$ vector; hence the comparison of $G 1$ and $G 2$. $\cos 1, \cos 2$, and $\cos 3$ are equal to $|\underset{h}{h}|^{2} \cos (\underline{h}, \underset{\sim}{e} j)$ for the three different waves as given in Eq. (16). P1, P2, P3, PT1, PT2, and PL have the same meaning as defined in Eq. (14). Loop 41 loads into $A$ the nine different coefficients corresponding to the combinations of $X$ and $Y$.

Equation (7) applies equally weli to either a bcc or fcc structure; one simply has to load the values of $\mathrm{LL}, \mathrm{M}$, and $\mathrm{MI}$ that define the positions for the desired structure. However, the TDS formulation is specific to the fcc lattice and would require modification for a bcc lattice. 
Once loop 9 is completed in DIFPUSE, all the coefficientz have been set up and STAT is called. The dimensions of IX, AS, X, AJ, ard AX must be at least NUH, the number of unknowns. Loop 15 forms what 18 known as the coefficients of the normal equations, AA. LOOp 50 is executed nine tines for the different combinations of $X$ and $Y$, but $a$ complete solution is obtained only for the fifth pass. Loop 62 wdifies AAA for subsequent solution. Locp 61 loads AAA into AA. Loops 2, 3, and 4 calculate the correlation tetween the various terms in the observations. XX must be made an identity matrix; then MATQ inverts $M$ leaving the inverse in $X X$. DET is the value of the deterninant. Loops $2 \mathrm{C}$ and 17 calculate the correlation between the errors. The solution is in $A X$, the calculated intensities in $B$, and the errors in AS. Variable ERI sums the residuals for each value of $2 \theta$. 'oop 31 calculates the various componezts of intensity: specifically Al is due to the alpha series, A2 the linear terms, A3 the quadratic and cross terms, and 14 the TDS term for selected traces.

On returning to DIFFUSE, a complete printout of the observed int.nsity, the calculated intensity, and the difference is executed. Roughly 2 min of IBM $360 / 91$ time is required for a solution of 44 values from 4032 observations.

\section{CHANGES IN THE PROGRAM}

Some care has been used in writing this program to make it reasonably efficient in the use of computer time. Alternate methods of handing the large numbers of sines and cosines could materially reduce the tive required to calculate the coefficients, giving perhaps a 107 overall savings. However, a wiser expenditure of time would be to put these coefficlents on tape such that for successive runs these coeffictents are not recalculated.

The progras must be modified to accept data in other formats, so one may be tempted to redesign the progran to accept many different formats. Offhand this would seen 80 difficult as to be 111 advised, unless of course one had with each observation its coordinates; In that case the modifications are trivial. 
In general several runs must be made to ensuxe that more or less optimum combinations of parameters are being calculated. In the present program this requires making dimensional changes in common blocks and In dimension statements, a process that is prone to error. Since one may use variable dimensions in subroutines, one can rather easily make the changes to simplify this problem. One simply uses a master program to define the overall size of the comnon blocks and specify the variables that define the wiay in which the blocks are used in the subroutines. Subsequent changes are entirely restricted to the main program and can be very simple.

The way in which ihe TDS was represented appeared to be adequate for the copper-aluminum data. However, one might well want to use a more rigorous representation if for no other reason than to judge the adequacy of the present representation. Provided one retains the elas:ic constant sitios, $X$ and $Y$, then it appears entirely feasible to solve the secular equations for each observation and thus reduce the approximations. One must obiain a different solution for each combination of $X$ and $Y$, and should this; represent appreciable computer time then the results could be stored on tape for later runs. One couli also use additional interaction parameters, but this tends to complicate the solution. It is simpler to use low-order $\varepsilon$ and $\rho$ terms instead, and they should be just as satisfactory.

There are otiser possible problens in tying to repiesent the TDS: at reduced temeraiures the different modes are not equally excited; at higher temperatures one will have higher orders of TDS. How to best handle these problems remains to be workad sut. It would be practical co simply use Eq. (7) and include restrints to restrict the curvature In the $\varepsilon$ and $\rho$ series in those regions where this intensity was slowly varying, as was done for the $\alpha$ series for the copper-aluminum data. ${ }^{17}$ One would now have to calculatc many more terms, and this could pose a problem.

${ }^{17}$. O. Williams, "Short-Range Structure in a Copper 16 Atomic Percent Aluminum," to be sumitted for publication. 
Many alloy systems show extra intensity near the Bragg peaks, which on precipitation leads to the so-called side bands. The present representation of the TDS is not capable of fitting this intensity. If one were to include enough terms in the $\varepsilon$ and $\rho$ series to represent this feature, then 111 couditioning will very likely result, and one must use supplementary conditions as noted above, possibly leaving out the TDS expression entirely.

\section{TES? ING}

The program must be properly implenented to give correct results. A fairly comprehensive initial test can be made as follows. First the program is implemented just as listed in this report and then run after removing the C's from the first colum of the two test cards listed early in the program. Wher this is done the observations are random numbers litween zero and unity. The solution should give correlation matrices very similar to those listed in Appendix B. The first coefficient, $\alpha_{0}$, should have a value close to 5.0, and all the other coefficients should be z.ero within about 2 standard errors. The determinant should be approximately $1.2 \times 10^{13}$, and the variance should be $4.3 \times 10^{-5}$. And finally the results should be insensitive to values of $X$ and $Y$.

We checked this frogram very carefully, and hopefully it is free cf significant errors. The author would appreciate any errors being brought to his attention and in turn wili notify other known users.

\section{DISCUSSION}

We have already indicated that certain problems can arise in a regression analysis but. do not occur in a Fourier analysis, but these may be handled in a st.raightforward manner. Two ninor advantages of the present method are that the correct $x$-ray scattering factors are used and weighting is used to correct for the varying precision of the observations. These will result in only modest improvements in the solution. 
This method is cousidered to have several major advantages. The first is that the observations may be made with considerable freedom, and all observations can be included in the analysis. And secondly we obtain a complete error analysis. What night turn out to be the greatest advantage is that the method necessarily computes the residuals. If from these data one establishes the presence of systematic errors and is able to identify and reduce them, then a significant improvement in the solution may result. One could do the same thing after having obtained a solution by separation, but it is less 1ikely to be as compiete and to cover the same range in reciprocal space.

\section{ACKNOWLEDGAENT}

Anong the several people at the laboratory who have contributed to this work, Cullie J. Spariks, Jz., deserves spectal mention. 
APPEDDIX A 
POSBA DIFTOSE

DIERESIOE LDD(60) , PEI(50) , PE2(60), OR (60), PBA (60) , FQ(50) .

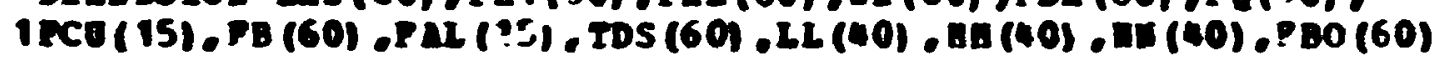

conuon $/ \mathrm{A} / \mathrm{A}(16,59)$. B (16,44),C (24,59).D(22,40)/B/AI (16, 59) . B I (16.

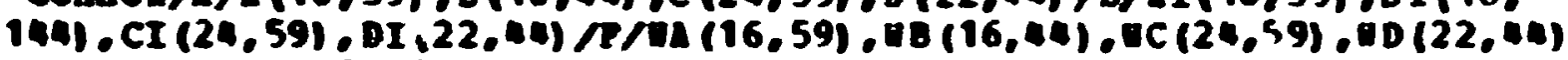

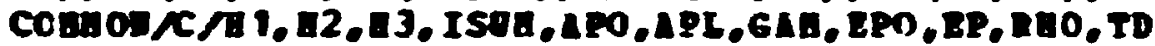

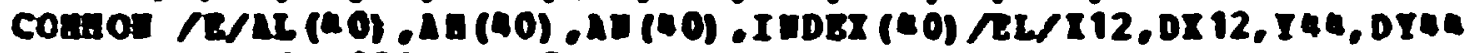

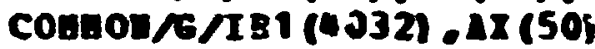

BATn PAL/13..12.46,11.32,10.20,9.30,8.58,7.97,7.41,6.87,6.34,5.82

$1.5 .33,4.86,0.02,0.02 /$

DIT FCV/26.8, 26.23,25..23.36,21.59,15.78, 18..16.27,14.56, 13.16

$1.11 .81,10.81,9.56,8.64,7.84 \%$

ALAG $=1.54178510=3.643$

$x 12=0.750 \times 12=0.06351+4=0.50050144=0.016$

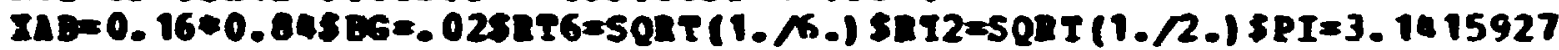

ER-4. *PI**2*IABSIBO=2.*R

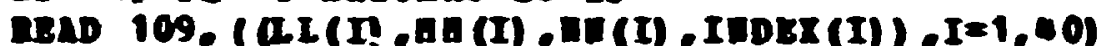

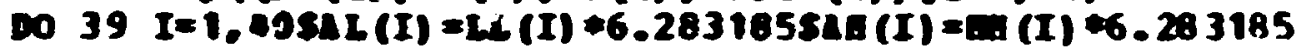

39 III (I) $=I=(I) * 6.283185800, I=1,16$

1 DED 100, ( $(I, J, J=1,59) 5002 I=1,16$

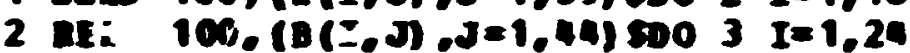

3 REN 100, (C(I,J) .J=1,59) 500 \& $I=1,22$

a RAD 1G., $(0(1, J), J=1,44)$

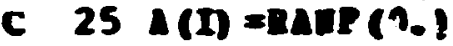

C $2525 I=1,9032$

D0 $6 I=1.605 I=(I-1) * 0.01745335 P(I)(I)=\cos (x) \$ P g 2(I)=\sin (x)$

TEST

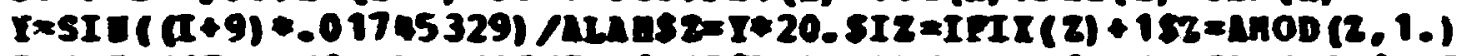

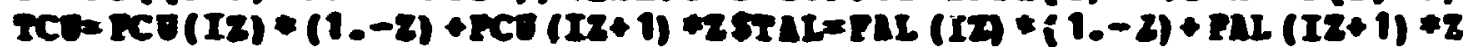

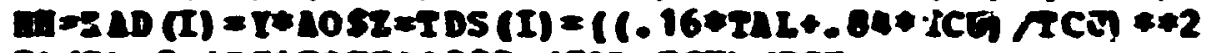

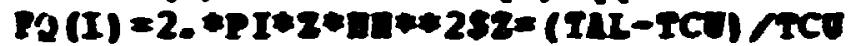

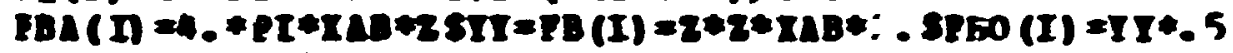

5 Un $(I)=V(2 .-59 /(I+43)) * .002 * \cos (I I+9) * .01745329)$

$D 620 I=1,003:$

20 or $(I)=0$ IS IS $=0$

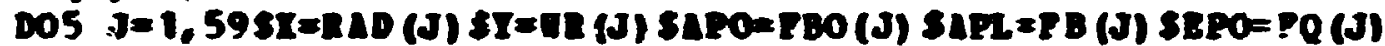

TD=T DS (J) SCAR= FBA (J) SDOSI=1, 16SI I=2*I-1SISUR =ISES+ 1SI RI (ISOR) =J

$z=11, J) \operatorname{sIF}(2.6 T-0)$ DL $(I, J)=I /(2+B G)$

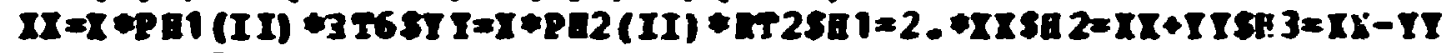

5 CALB SEIES

DO $7 J=1,4 A S T=J+15 S I=R A D(K) S I=D R(K) S A P O=F O(K) S A R L=F B(K) S E P O=P Q(K)$ TD=T DS (K) SGAE= FBA (R) \&DO 7 I=1, 16\$II=2*ISISOA = ISON+ 1

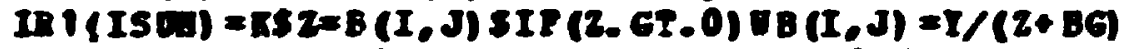

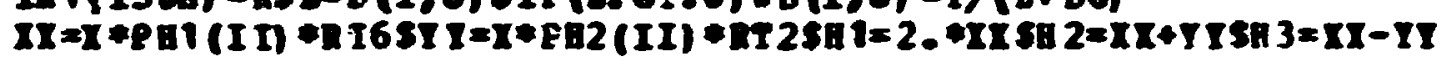

7 CALL SEIES $\$ B 3=0$.

DC $8 J=1,59 S I=R \triangle D(J) S I=V R$ (J) $\$ \angle P O=F B J(J) ~ S A P L=F B(J) \$ E P O=P Q(J)$

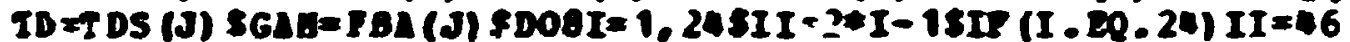

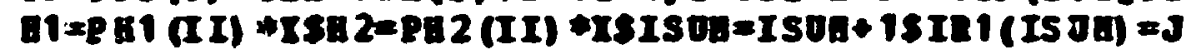

$z=C(I, J) \operatorname{sI}(2.6 T .0) \mathrm{WC}(I, J)=I /(2+86)$

8 Cali seares

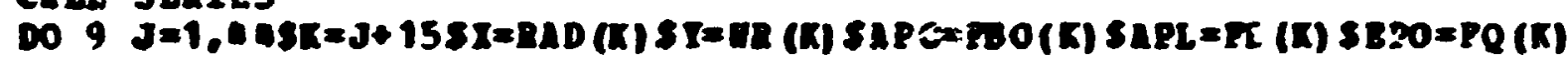

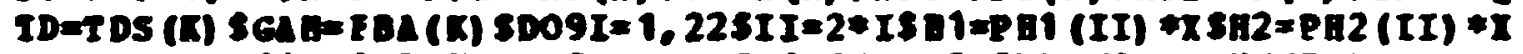

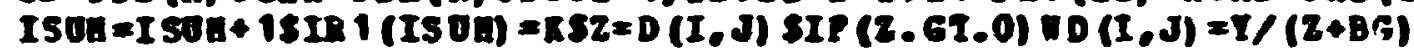

9 CALL SERIESHCALL STAT

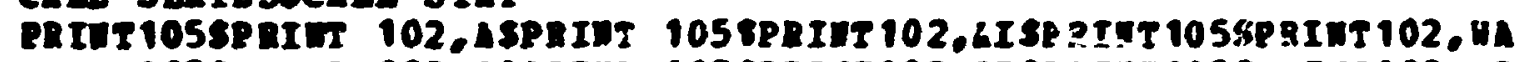

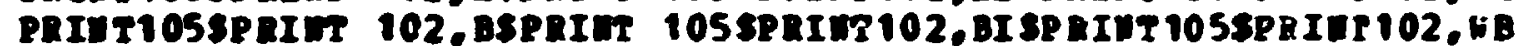

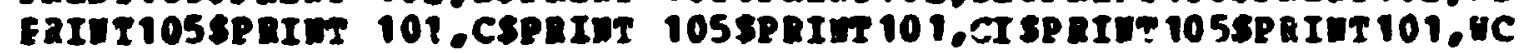

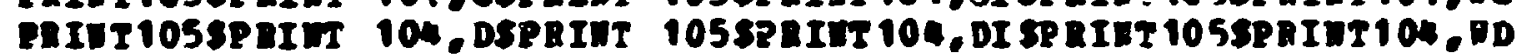

100 FongAT (26?3.3)

101 poBnat (180,3P24R5. O) 


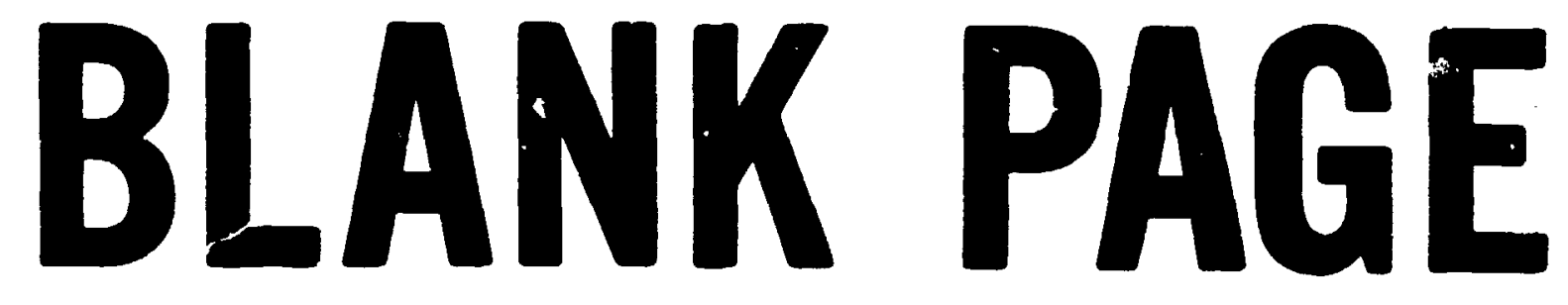




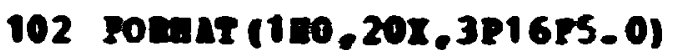

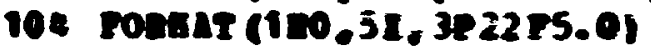

105 ponere (181)

109 romar (B) $(23,2 I 1, I 2,3 \pi))$

10

SOMOJTIE SEIES

DIRESme croos

cerinor 21, C., do

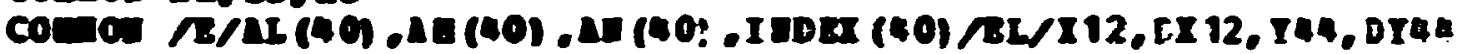

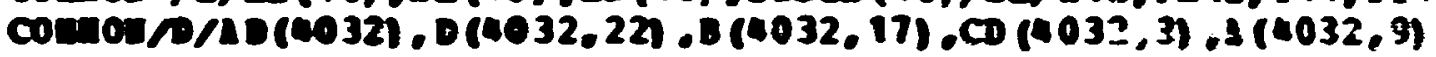

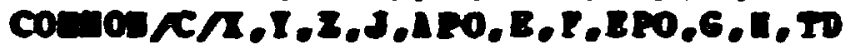

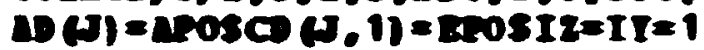

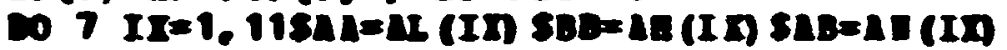

$\operatorname{cos0}(1.2,3,4.5,6)$ IDDE (ID)

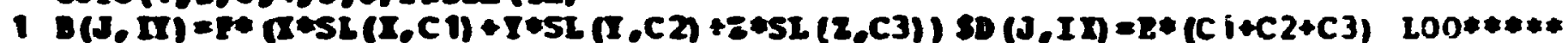
$C(I)=0 *(I+I+C) 1+I * I * C 2+2 * z+C 3) x(I z+i)=0 *(I * I *(C 2 * C 3)+1 * I *(C 1+C 3)+$

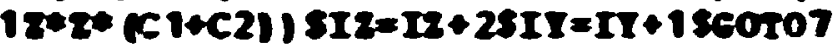

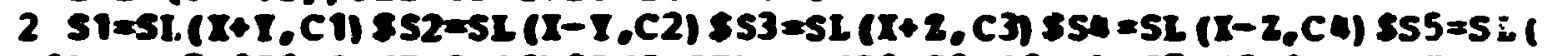
$1 I+2, C 5) 556=5 \mathrm{~L}(I-2, C 6)$ sD $(J, I I)=E+(C 1+C 2+C 3+C 4+C 5+C 6) 5 B(J, I Y)=$ $25 *(x *(.51+52+53+54)+I *(55+56+51-52)+2 *(53-54+55-56)) \$ I I=I I+1$ $C(I Z)=\theta *(I * I *(C)+C 2 * C 3 * C 4)+I * I *(C)+C 2+C 5+C 6)+2 * 8$

$2 *(C 3 * 4+C 5+C G)$ ( sC $(I 2+1)=(I * I *(C 5+C 6)+I * I *(C 3+C 4)+2 * 2 *(C 1+C 2))$

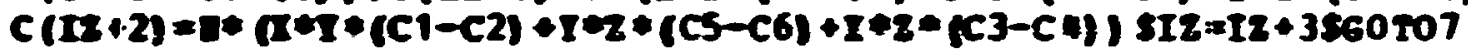

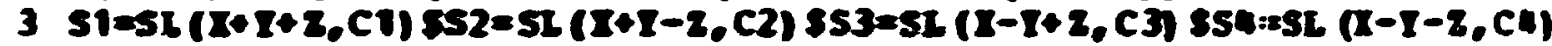

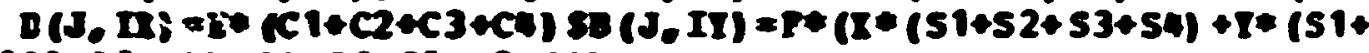

$152-53-59)+2 *(5+52+53-54)$

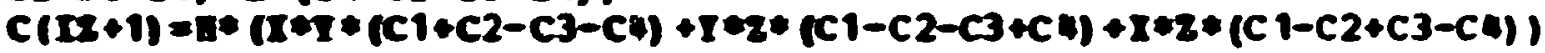

$C(I I)=0 *(I+I+I+I+2 * 2) *(C 1+C 2+C 3+C a) \$ I 2=I Z+2 s I I=I I+1860 r 07$

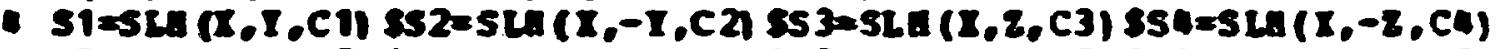

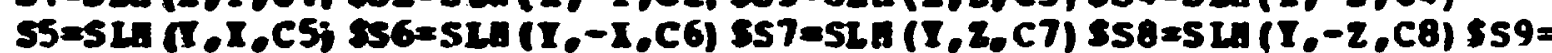

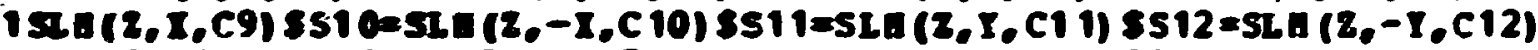

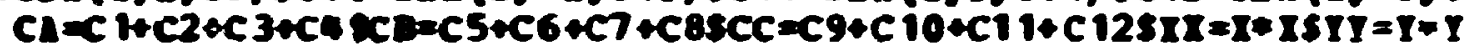
$22=2+250(\mathrm{~d}, \mathrm{In})=(\mathrm{CA}+\mathrm{CB}+\mathrm{CC})=2$

$E(J$. IT $)=(I *(S 1+52+53+54)+1 *(55+56+57+58)+2 *(59+510+51+512)) * F$

D $(J . I I+1)=P *(x *(55-56+59-510)+I *(5)-52+511-512)+2 *(53-54+57-58))$

$C(I 2+3)=\pi *(I * I *(C 1-C 2+C 5-C 6)+I * 2 *(C 3-C+4+C 5-C 10)+1 * 2 *(C 7-C 8+C 11-C 12$

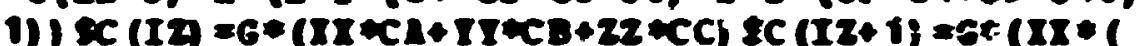

$2 C 5+C 6+C s+C 10)+I I *(C)+C 2 * C 11+C 12)+22 *(C 3+C+47+C \theta)) s C(I 2+2)=6 *$

(II* $(C 7+C 8+C 11+C 12)+I I * i C 3+C 4+C 9+C 10)+22 *(C 1+C 2+C 5+C(1))$ sI $2=I 2+4$ $I I=I I+2500 T 07$

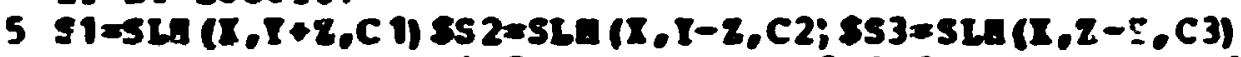

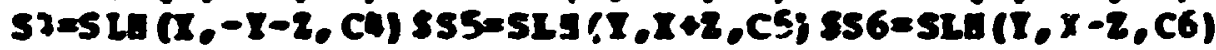

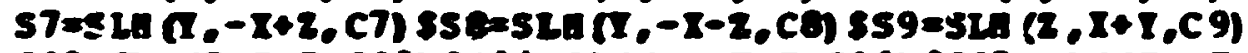

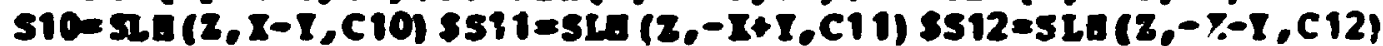

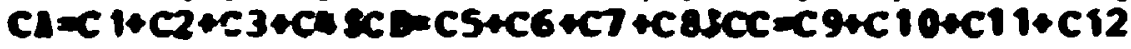

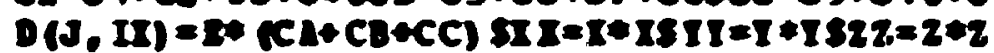

$E(J . I I)=F *(x *(51+52+53+54)+I *(55+56+57+50)+2 *(59+510+511+512))$

$B\left(J_{0} I Y+1\right)=F *(\mathrm{R} *(55+56-57-53+59+510-511-512)+1 *(51+52-53-54+59-510$

$1+51:-512)+2 *(51-52+53-54+55-56+57-58)($

$C(I z+2)=1 *(I+I *(C)+C 2-C 3-C 4+C 5+C 6-C 7-C 0)+I * 2 *(C 5-C 6+C 7-c 8+C 9-C)$

$10+C 11-C 12)+I * 2 *(C 1-C 2+C 3-C H+C 9+C 10-C 11-C 12))$ sC (IZ*3) $=H *(I * Y *(C 9$

$5-(10-c 11+C 12)+1 * 2 *(c 1-C 2-C 3+C 4)+1 * z *(c 5-C 6-c 7+C 8))$

$C(I z)=C *(I I * C A+I I * C B+2 \varepsilon * C C) ~ S C(I Z+1)=6 *(I I *(C B+C C)+I Y *(C A+C C)+$

$822 *(C \lambda+C 2) 19 I 2=I 2+45 I I=I I+2500107$

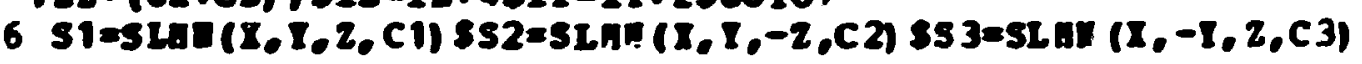

LLOF*at

LLL LEO+estat 2

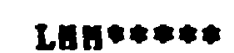

\footnotetext{
6 sl
} 


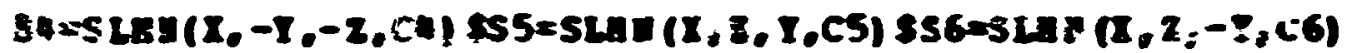

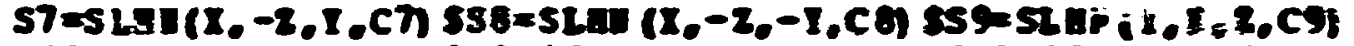

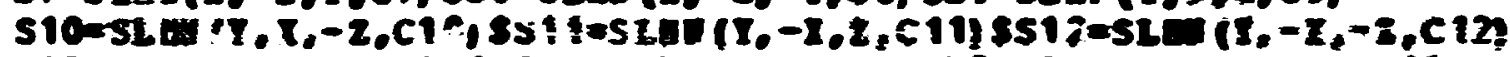

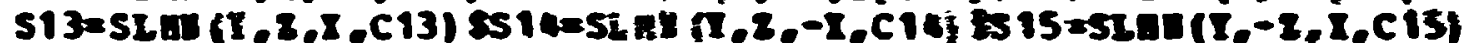

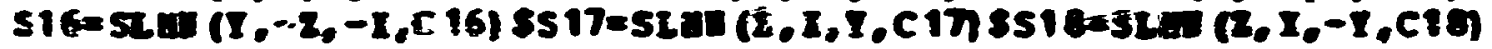

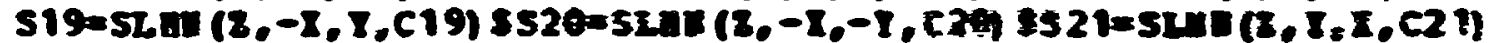

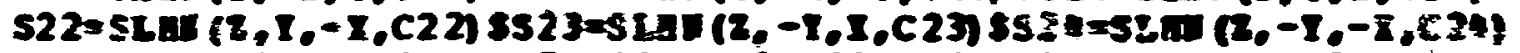

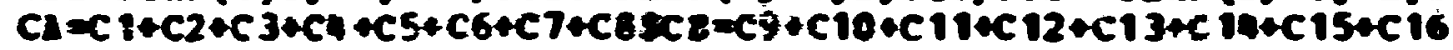

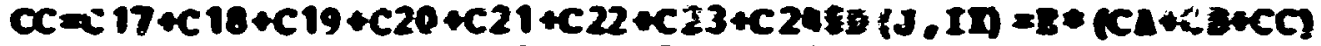

$B\left(J_{0} I Y\right)=F *(\bar{x} *(3)+52+53+5 i+55+56+57+50)+7 *(59+510+511+512: 513 *$ $151 * 515+516)+2 *(517+518+519+520+521+522+52+5241)$

D(J. II $+1 i=$ P* $a *(59+510-511-512+517+510-519-520)+5 *(51+52-53-54$ $2+521+522-523-524)+3 *(55+56-57-50+513+514-515-5161)$

$E(J, I I+2)=P *(x *(513-514+515-516+521-522+523-524)+I *(55-56+57-58$ $3+517-518+519-520)+2 *(51-52+53-50+59-510+511-5121) 517=17+3$

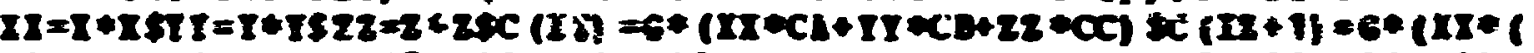

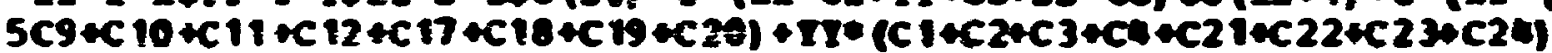

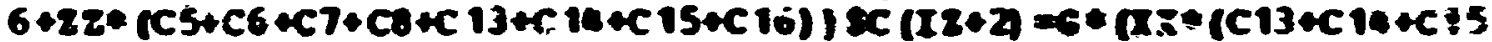
$6+C 16+C 21+C 22+C 23+C 24)+1 T *(C 5+C 6+C 7+C 8+C 87+C 18+C 15 \times C 20)+22 *(C 1+C 2$

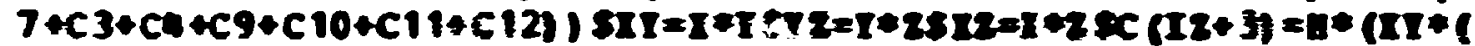

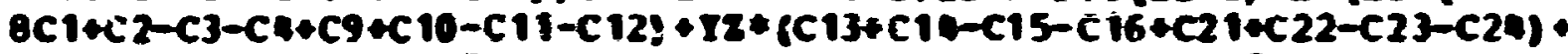

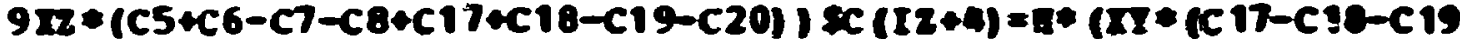

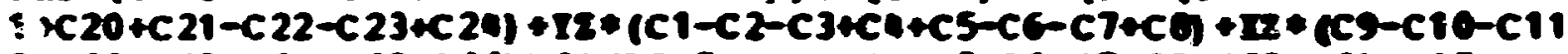

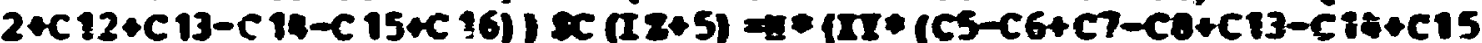

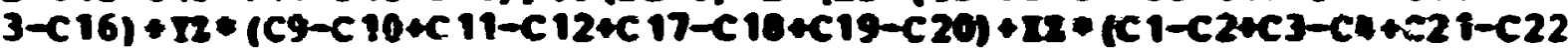
$+423-C 241) \$ 2 z=12 * 6$

7 COIFIU⿴囗S SDC $+2 \quad I=2,3$

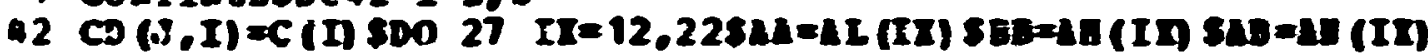
COTO $(21,22,23,24,25,26)$ I IDEX (II)

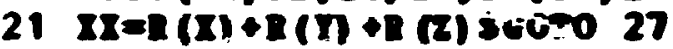

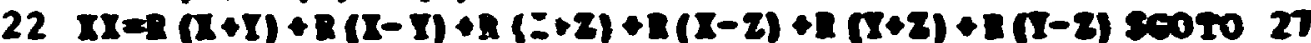

$23 x x=1(I+I+2)+R(x+I-2)+2(x-I+8 ;+R(x-I-8)$ seoro 27

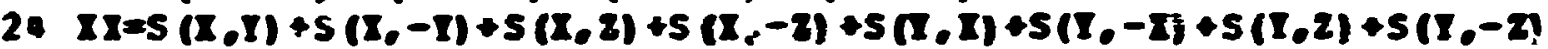
$1+5(2, x)+5\left(z_{0}-x\right)+5(2, I)+5\left(z_{0}-1\right)$ s0010 27

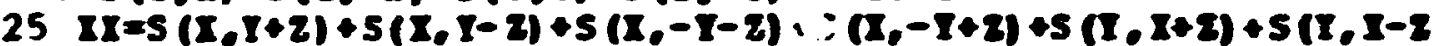

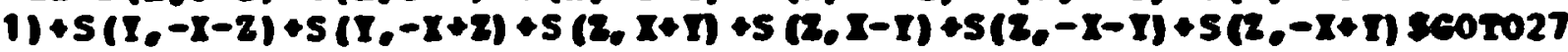

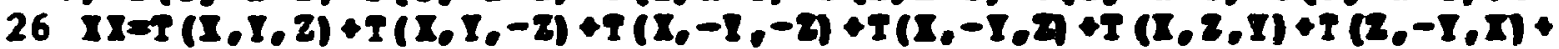
$I T\left(x_{0} z_{0}-I\right)+T\left(x_{0}-z_{0}-I\right)+I\left(x_{0}-z_{0} I\right)+I\left(I_{0} I_{0} z_{1}\right)+I\left(x_{0} x_{0}-z_{1}\right)+I\left(x_{0}-x_{0}-z_{0}\right)$

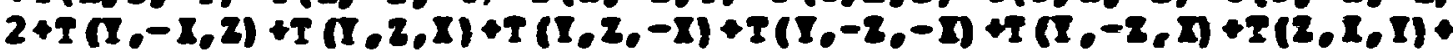

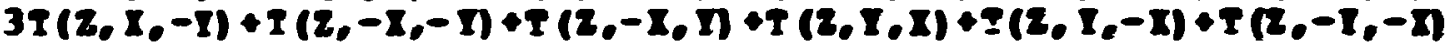

$27 D\left(J_{0} I X\right)=E * I X$

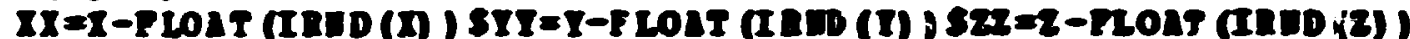

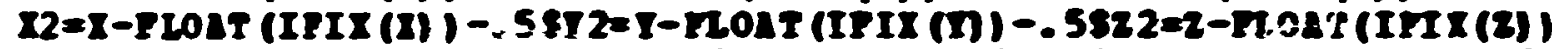

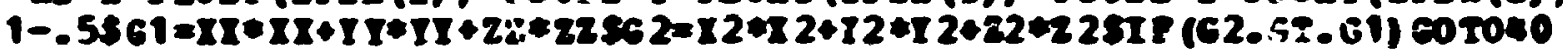
$X X=I 25 I Y=12522=225 \in 1=62$

$40 \quad 28=I I * I I+I I * I Y S Z L=I * I I+I * I I S \cos 1=(2 * 22+24) * 2 / 21$

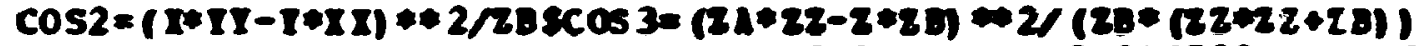

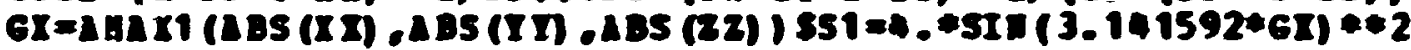

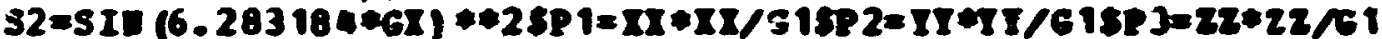
$P 12=P 1 * P 2 S P T Y=4 . * P 12 *(1 .-j . * P 3)$ SPR2=4.*P3*(P1+P2-6.*12) $P 123=P 12 * P \quad 3 * 27.3 P L=P 1+P 125 P 0=1 .-P L-P 123$ Do41 $I=1,95 I X=(I-1) / 35 I=X 12+0 X 12 * I X S I=I 44+0 I 44 *(I-1-3 * I X)$ $V P=(1 .-x+I)+2123$

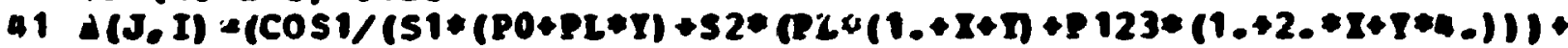
$12032 /(S 1 *(I *(P O+P T I)+P T 2)+52 *(11 .-I-I) * P T 1 *(2 . * I-1) * P I 2+.1 P)) *$ $2 \cos 3 /(S 1 *(I *(P O+P T 2)+P I I)+52 *(11,-I-I) * P T 2 *(2 . * I-1) * P T 1+.T I) * T D$ METO ALSETD 


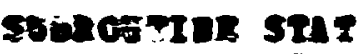

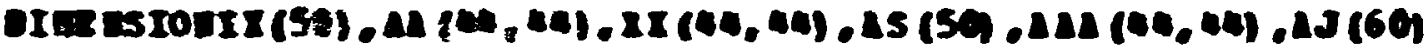

Dreseston terise)

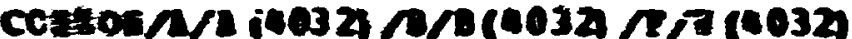

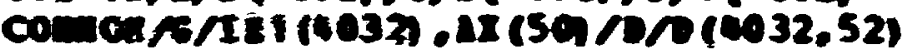

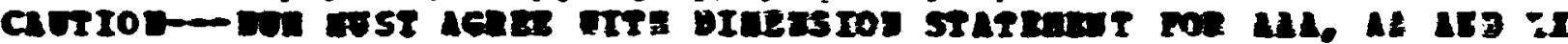

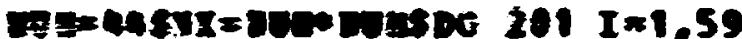

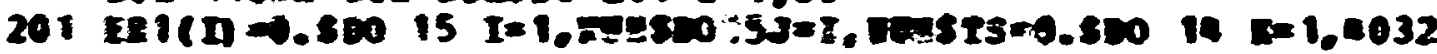

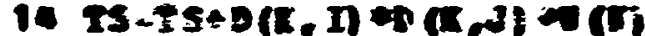

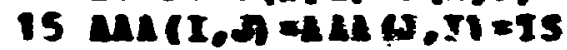

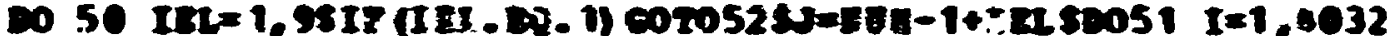

$51=(I, D) \Rightarrow(x, d)$

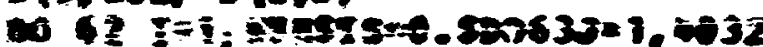

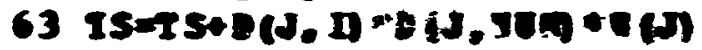

$62 \mathrm{MA}(1,50 \mathrm{~g}$.

52 2061 I: 1.01

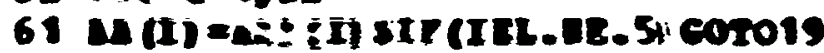

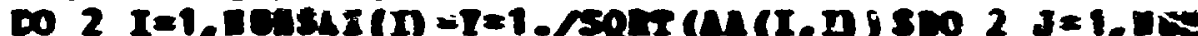

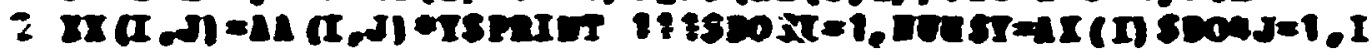

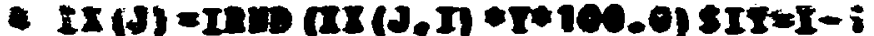

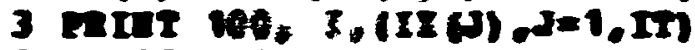

$19510 I=1,1 \mathrm{I}$

18 ER $(\mathrm{T})=0.50021 \mathrm{I}=1, \mathrm{TL}$

21 Ix (a.I) at.

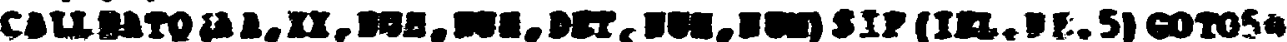

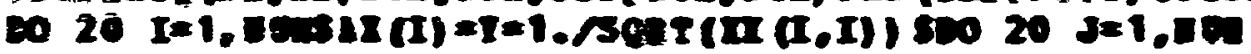

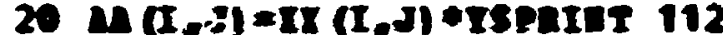

00 1: I=1, COTSI=AN (I) SIT=I-180017J=1, I

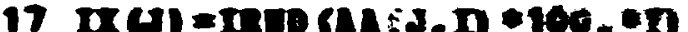

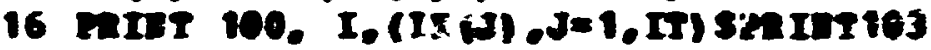

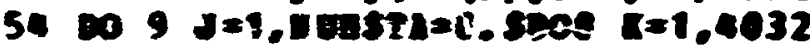

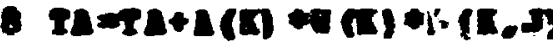

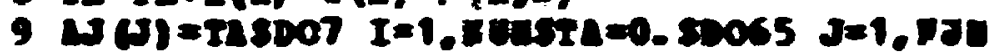

$65 x=2 x+x(1, \pi) * N(3)$

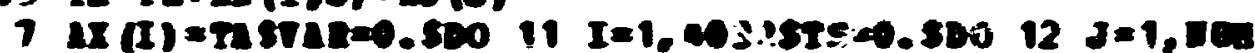

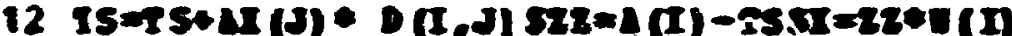

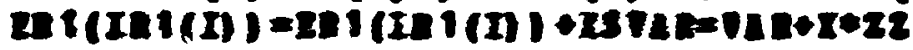

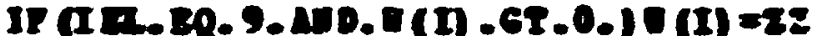

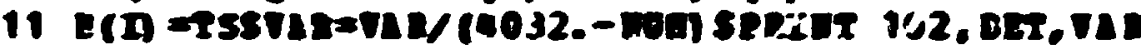
Do $13 \quad I=1, \mathrm{Nu}$

13 is (I) =sent (vanex (I.I):

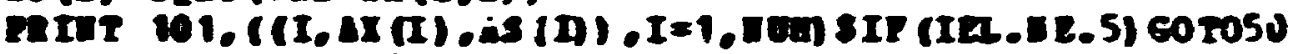

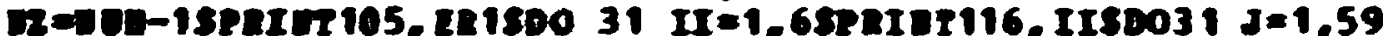
$0020141,42,93,94,95,461$ II

11 12.0 16-15s907047

42 Lej* 10- 58007047

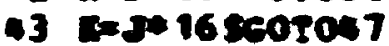

it $I=j * 24+16258007047$

$45=3 * 24+16328 \sin 2 \pi$

$467=0224+1538$

$47 \quad 21=\triangle 2=13=0.300 \quad 32 \quad I=1.23$

32 II $1+0(K, I) * 1 X(x)$ spo $33 I=24.40$

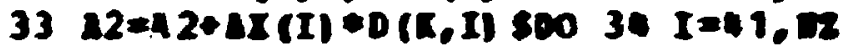

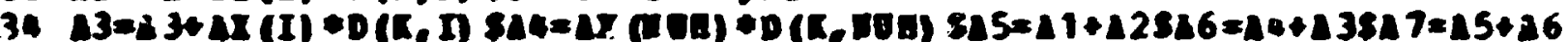

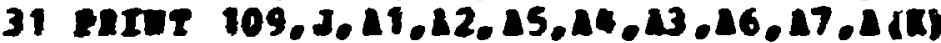

50 corringe

100 porast $13,12,433$

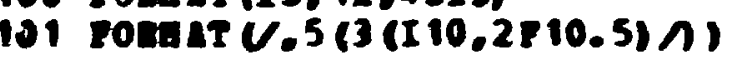

103 rongst (1B1) 


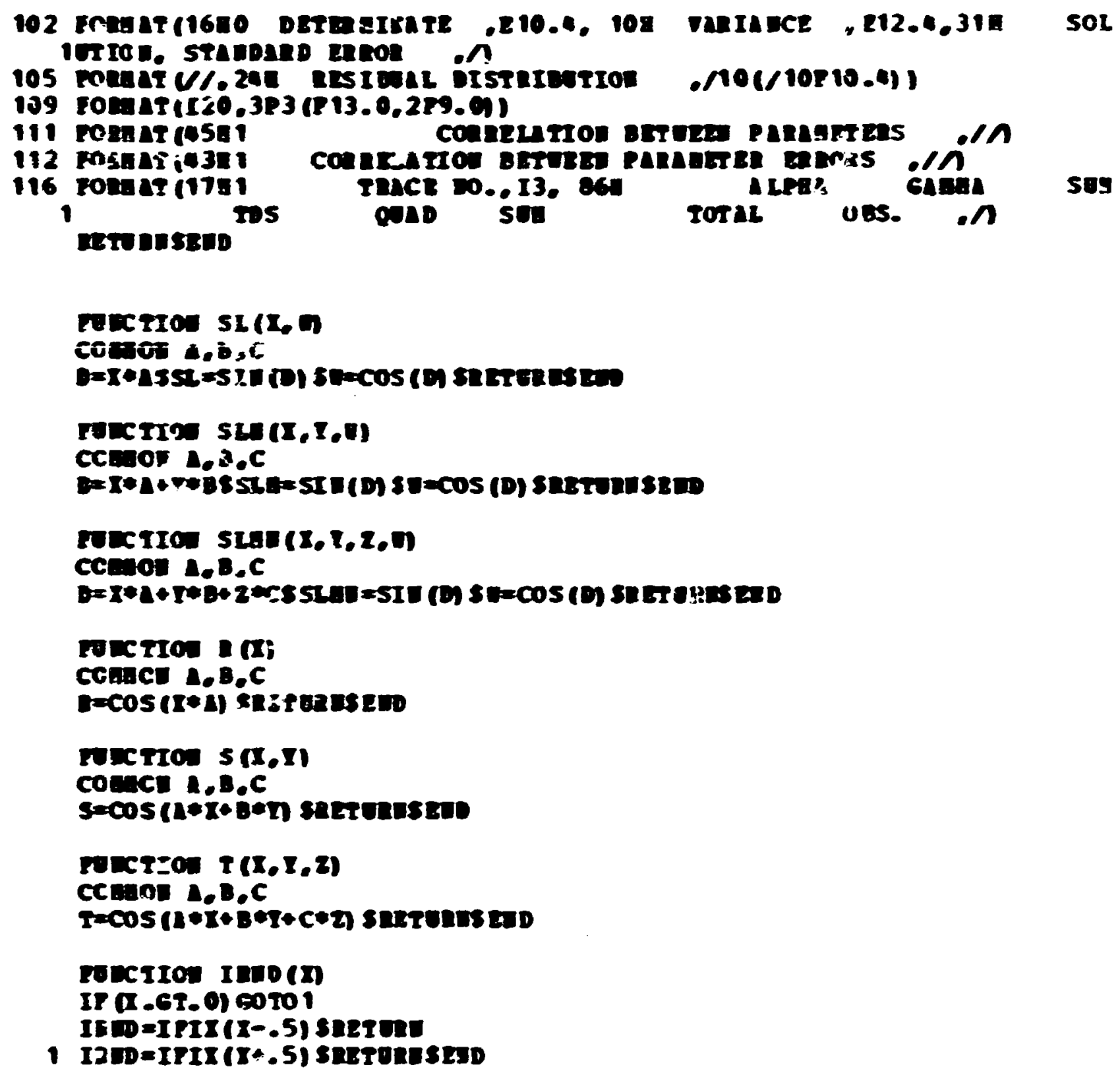


APPEDIX B 



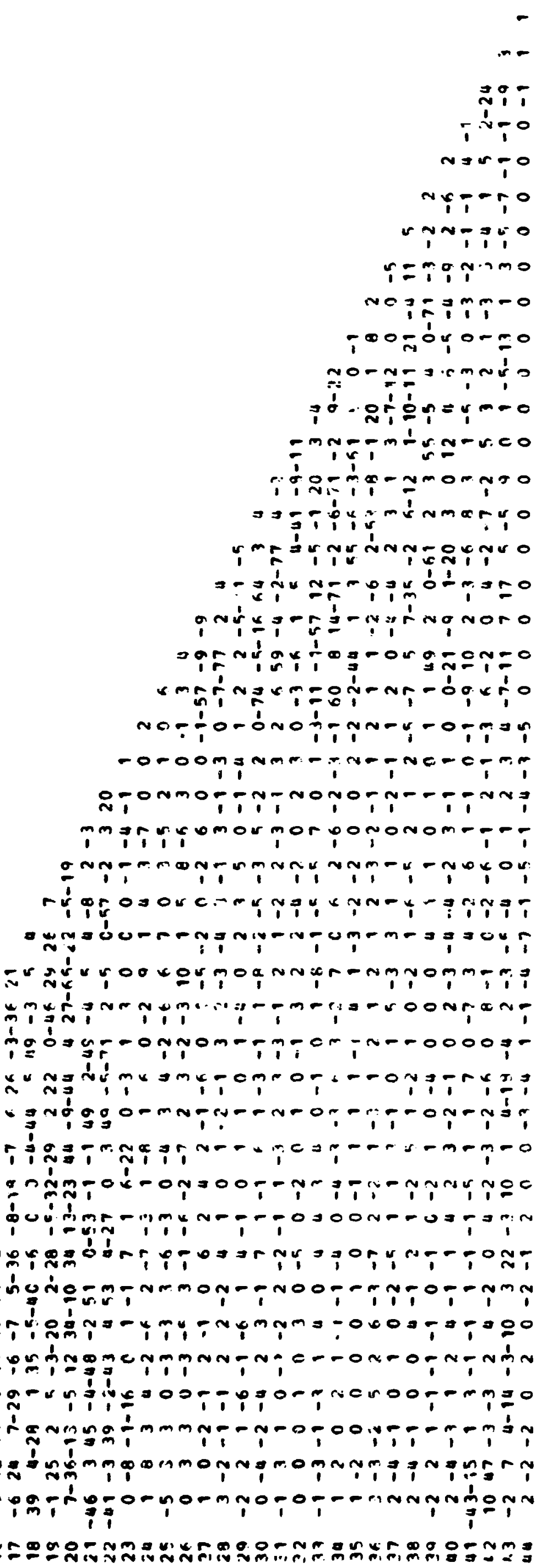

